\title{
COVIDSafe thoracic surgery: Minimizing intraoperative exposure to aerosols
}

\author{
Michael Seco, BMedSc, MBBS, PhD, ${ }^{\mathrm{a}, \mathrm{b}}$ James Wood, BSc, MBChB, FRCS(Ed), ${ }^{\mathrm{b}}$ and \\ Michael K. Wilson, MBBS, FRACS, ${ }^{b}$ Sydney, Australia
}

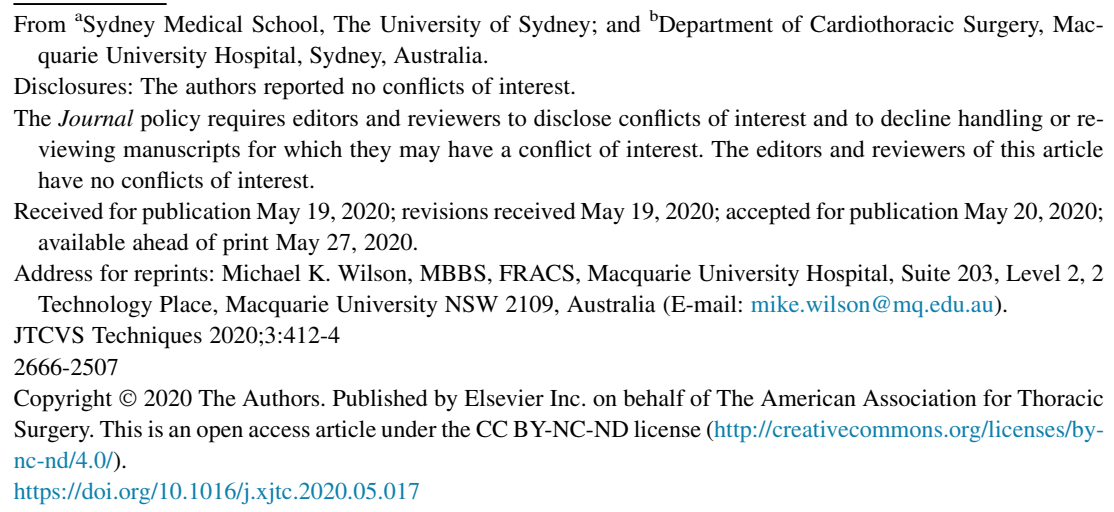

https./doi.org/10.1016/j.xjtc.2020.05.017

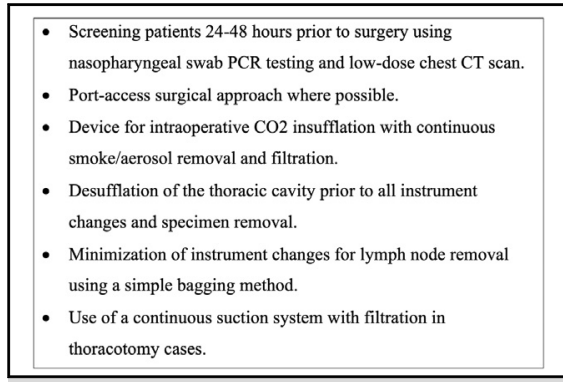

Steps to minimizing intraoperative exposure to aerosols generated during thoracic surgery.

\section{CENTRAL MESSAGE \\ Modifications to reduce viral transmission during thoracic surgery include effective screening, using a port-access surgical approach where possible, and a system of aerosol removal and filtration.}

See Commentaries on pages 415 and 417.
The novel coronavirus (severe acute respiratory syndrome coronavirus 2 [SARS-CoV-2]) pandemic poses unique challenges to thoracic surgery. First, the risk to postoperative thoracic patients is significant: mortality of $20 \%$ to $40 \%$ has been reported in small case series. ${ }^{1,2}$ Second, the potential for aerosolization during surgery and viral transmission to the operating team has been acknowledged. ${ }^{3}$ Although there are currently no data on intraoperative SARS-CoV-2 transmission, it is known to have similar stability and viability to severe acute respiratory syndrome coronavirus 1 in aerosols ${ }^{4}$; other viruses are known to transmit through surgical smoke and aerosols ${ }^{5,6}$; and there is a high incidence of coronavirus disease 2019 (COVID-19) in operators exposed to the airways. ${ }^{7}$ Although many countries, including our own, have placed a temporary suspension on elective procedures, emergent/urgent thoracic patients will continue to require surgery, and relaxations of elective surgery suspensions will need to occur in the near future. We share here how we have modified our operative technique to minimize the operating team exposure to aerosols during thoracic surgery (Table 1). Informed written consent was obtained by all patients.

Risk mitigation begins with effective screening. All patients undergo a nasopharyngeal swab and polymerase chain reaction testing for SARS-CoV-2 24 to 48 hours preoperatively, although this has limited sensitivity and a false-negative rate. ${ }^{8}$ Patients also undergo a low-dose computed tomography scan of the chest to detect lung parenchymal changes, ${ }^{9}$ ideally $<48$ hours before the scheduled operation time, as this improves the detection of possible COVID-19. This is in place of a routine radiograph of the chest that would normally occur at this time.

Operative modifications aim to create a completely closed system within the thoracic cavity, so that aerosols generated within the chest cannot escape into the external environment. Key to this is (1) a port-access-only surgical approach (in our case, robotic-assisted), and (2) a system of aerosol removal and filtration. We currently use the PneumoClear system (Stryker; Kalamazoo, Mich), although similar systems from other manufacturers exist. ${ }^{10-13}$ This system has 2 modes of function: insufflation and desufflation. Insufflation introduces humidified carbon dioxide $\left(\mathrm{CO}_{2}\right)$ into the chest at a controlled pressure while the system simultaneously removes smoke generated by diathermy via paired suction. This is traditionally used to 
TABLE 1. Key steps to minimizing intraoperative exposure to aerosols generated during thoracic surgery

- Screening patients $24-48 \mathrm{~h}$ before surgery using nasopharyngeal swab PCR testing and low-dose CT scan of the chest.

- Port-access surgical approach where possible.

- Device for intraoperative $\mathrm{CO}_{2}$ insufflation with continuous smoke/ aerosol removal and filtration.

- Desufflation of the thoracic cavity before all instrument changes and specimen removal.

- Minimization of instrument changes for lymph node removal using a simple bagging method.

- Use of a continuous-suction system with filtration in thoracotomy cases.

$\overline{P C R}$, Polymerase chain reaction; $\mathrm{CT}$, computed tomography; $\mathrm{CO}_{2}$, carbon dioxide.

improve surgical view, although it has the added benefit of removing any aerosols that are generated. Desufflation is performed by stopping insufflation and rapidly suctioning the gas within the chest cavity. The evacuated gases pass through a tubeset containing an ultra-low particulate air (ULPA) filter, which captures and removes $99.999 \%$ of particulates and micro-organisms $>0.1 \mu \mathrm{m} .{ }^{14}$ The PneumoClear system also prevents overpressurizing the thoracic cavity through a venting valve, which passes through a high-efficiency particulate air (ie, HEPA) filter that captures $99.97 \%$ of particles $>0.3 \mu \mathrm{m} .{ }^{14}$ Coronavirus particles range from 60 to $140 \mathrm{~nm}$ in diameter ${ }^{15}$ and are generally dispersed in larger droplets, and thus should be effectively removed; however, this has not been directly tested yet.

Figure 1 depicts the setup for this system. Four ports are created for the robotic system ( $\mathrm{Da}$ Vinci $\mathrm{Xi}$; Intuitive

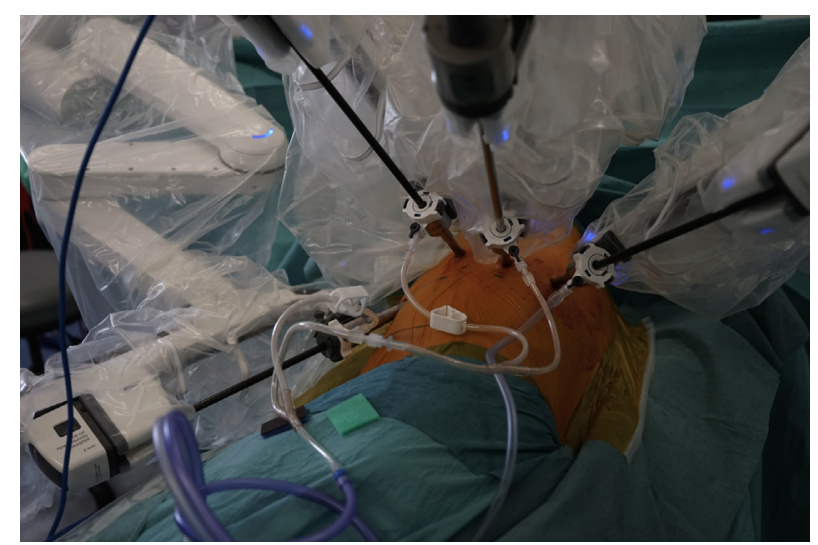

FIGURE 1. Setup for robotic-assisted thoracic surgery using the PneumoClear system for intraoperative aerosol removal and filtration. Four standard ports are inserted, and the robot docked. $\mathrm{CO}_{2}$ insufflation is connected to 1 port (clear tubing) and smoke evacuation/desufflation is connected to the remaining 3 ports (purple tubing connected to a white 3-way splitter). During the operation, $\mathrm{CO}_{2}$ is insufflated while smoke and aerosols are continuously evacuated from the chest. Before all instrument changes and specimen removal, the desufflation function is used to evacuate the gas within the thoracic cavity.
Surgical, Sunnyvale, Calif). Small skin incisions are used when inserting the trocars and a low insufflation pressure is used to minimize leak around the ports. $\mathrm{CO}_{2}$ insufflation is connected to 1 port, whereas smoke evacuation and desufflation are connected to the remaining 3 ports. A circulating nurse controls the PneumoClear system and triggers desufflation; generally, additional staff in the operating room are not required.

Changing instruments through the ports during the procedure disturbs this "closed system." When an instrument is changed, the desufflate function is used to rapidly evacuate the thoracic cavity of gas and aerosols (Video 1). Once the new instrument is inserted, the insufflation/smoke evacuation is recommenced. In our experience, this adds a short amount of time to the procedure (approximately 10-15 minutes).

Specimen and lymph node removal also disturbs the closed system. During the procedure, any individual lymph nodes that are harvested are placed in a homemade catchment bag (a green surgical glove, with the fingers numbered) and set to the side to minimize exchanges (Video 1). Once all aerosol-generating surgery has been

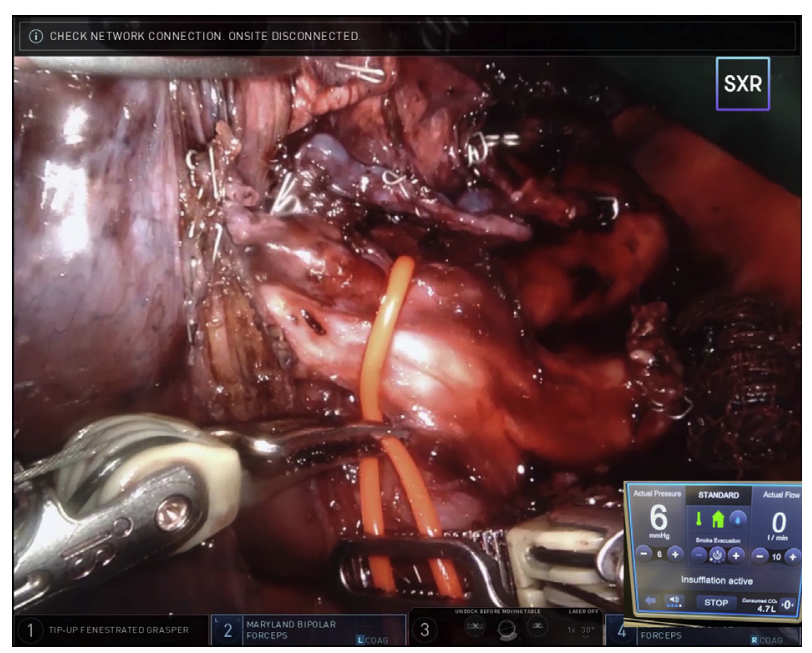

VIDEO 1. A pulmonary segmentectomy using a standard 4-port roboticassisted approach is shown. The PneumoClear system (Stryker) is connected to the ports (the system screen is pictured in the bottom right). Before any instrument change is made, the thoracic cavity is desufflated. A simple method is also used to minimize instrument changes for lymph node sampling. After desufflation, the instrument is removed, a green sterile glove with numbered fingers is introduced into chest, the instrument reinserted, and $\mathrm{CO}_{2}$ insufflation and smoke evacuation recommenced. Lymph nodes that have been resected are placed into the numbered fingers of the glove. Once the lung specimen is ready to be removed, the glove is placed in the endocatch bag with the lung and removed at the same time. The surgeon removes the lymph nodes from the glove and inspects the thoracic cavity before closing to make sure all material has been removed. Video available at: https://www.jtcvs.org/article/S2666-2507(20)30238-8/ fulltext. 
completed and the lung specimen is ready to be removed, the glove with lymph nodes is placed in the endocatch bag along with the lung. To remove the endocatch bag, the thoracic cavity is desufflated as described, and one of the ports is removed. Continuous, high suction is then applied to one of the remaining ports using the Neptune Waste Management System (Stryker), which also contains a ULPA filter, to prevent outwards airflow through the open skin incision. This causes some lung re-expansion to occur, although this is generally not an issue at this stage. Once the specimen has been removed, the surgeon removes the lymph nodes from the glove and inspects the thoracic cavity with the endoscope to ensure all material has been removed. The operation is then completed by inserting a subpleural catheter and chest drain. The time taken to perform this process is minimized as much as possible.

It is not possible to use this closed system method in surgical approaches that involve small thoracotomies, or if conversion from a port-access approach is required. To the minimize risk in these circumstances, we use the PureView Active Plume Filtration Device and Neptune System (Stryker), which contain similar ULPA filters. These are connected to a separately placed port and used to provide continuous suction of intrathoracic gases to prevent aerosolized particles escaping through the thoracotomy as much as possible and exposing the operating team.

\section{References}

1. Cai Y, Hao Z, Gao Y, Ping W, Wang Q, Peng S, et al. Coronavirus Disease 2019 in the perioperative period of lung resection: a brief report from a single thoracic surgery department in Wuhan, People's Republic of China. J Thorac Oncol. 2020;15:1065-72.
2. Li YK, Peng S, Li LQ, Wang Q, Ping W, Zhang N, et al. Clinical and transmission characteristics of Covid-19-a retrospective study of 25 cases from a single thoracic surgery department. Curr Med Sci. 2020;63: 364-74.

3. Royal Australasian College of Surgeons, Clinical Expert COVID-19 Working Group, Collinson T, Hewett P, Hugh T, Padbury R, et al. Guidelines for safe surgery: open versus laparoscopic. A rapid review commissioned by RACS. Available at: https://umbraco.surgeons.org/media/5214/2020-04-15recommendations-on-safe-surgery-laparoscopic-vs-open.pdf. Accessed April 9, 2020.

4. van Doremalen N, Bushmaker T, Morris DH, Holbrook MG, Gamble A, Williamson BN, et al. Aerosol and surface stability of SARS-CoV-2 as compared with SARS-CoV-1 [letter]. N Engl J Med. 2020;382:1564-7.

5. Liu Y, Song Y, Hu X, Yan L, Zhu X. Awareness of surgical smoke hazards and enhancement of surgical smoke prevention among the gynecologists. J Cancer. 2019;10:2788-99.

6. Tran K, Cimon K, Severn M, Pessoa-Silva CL, Conly J. Aerosol generating procedures and risk of transmission of acute respiratory infections to healthcare workers: a systematic review. PLoS One. 2012;7:e35797.

7. Vukkadala N, Qian ZJ, Holsinger FC, Patel ZM, Rosenthal E. COVID-19 and the otolaryngologist: preliminary evidence-based review. Laryngoscope. March 26, 2020 [Epub ahead of print].

8. West CP, Montori VM, Sampathkumar P. COVID-19 testing: the threat of falsenegative results. Mayo Clin Proc. 2020;95:1127-9.

9. Fang Y, Zhang H, Xie J, Lin M, Ying L, Pang P, et al. Sensitivity of chest CT for COVID-19: comparison to RT-PCR. Radiology. 2020;Feb 19:200432.

10. ConMed. AirSeal(R) System. Available at: https://www.conmed.com/en/ medical-specialties/laparoscopic-robotic-and-open-surgery/general-and-bariatricsurgery/access/airseal-system/airseal-products/airseal-ifs-intelligent-flow-system. Accessed April 26, 2020.

11. Ethicon. Megadyne(TM). Smoke Evacuator. Available at: https://www. jnjmedicaldevices.com/en-US/product/megadyne-smoke-evacuators. Accessed April 26, 2020.

12. Northgate Technologies Inc. Nebulae I(TM) System. Available at: https://www. ntisurgical.com/nebulae-I. Accessed April 26, 2020.

13. Medtronic. RapidVac(TM) Smoke Evacuator System. Available at: https://www. medtronic.com/covidien/en-us/products/smoke-evacuation/rapidvac-smokeevacuator-system.html. Accessed April 26, 2020.

14. Institute of Environmental Science and Technology. IEST Recommended Practices. Available at: https://www.iest.org/Standards-RPs/RecommendedPractices/IEST-RP-CC001. Accessed March 26, 2020.

15. Zhu N, Zhang D, Wang W, Li X, Yang B, Song J, et al. A novel coronavirus from patients with pneumonia in China, 2019. N Engl J Med. 2020;382:727-33. 